\title{
EDITORIAL
}

nature

cell biology

\section{Building consensus}

\section{A group of Golgi researchers tackle controversies in the field head-on and emerge with a blueprint for future research.}

Controversies abound in science, and cell biology has its share of thorny issues. Spirited debates within fields can keep a research area stimulating for both insiders and outsiders. But, too often, in the inevitable backand-forth of publications supporting irreconcilable positions, fields can seemingly stagnate as it becomes increasingly challenging to resolve opposing viewpoints and make progress. Long-standing controversies can also stunt a field's growth by discouraging new researchers from entering the field. It is therefore in the best interests of all parties involved to find common ground. A group of researchers working on the Golgi have set about doing just that.

The structure of the Golgi apparatus, how it is partitioned and how proteins are transported across this compartment have been matters of debate. A group of researchers working on the Golgi convened in Barcelona earlier this year to discuss current views and to assess the strengths and weaknesses of published work. The meeting, organized by Vivek Malhotra (CRG, Barcelona), aimed to provide a forum for candid discussion of contentious issues, a goal that is often difficult to achieve in the context of traditional conferences with broad themes. The meeting addressed four important areas of Golgi biology; published papers were discussed in each session, which then concluded with summaries that were subsequently incorporated into a published report (J. Cell Biol. 187, 449-453; 2009). The participants plan to meet again in three years and, according to Vivek Malhotra, "The next meeting will be a real test of the impact of this meeting."

Consensus was reached on some fundamental issues but, just as importantly, these discussions identified critical questions that must be addressed in future work. Whether the Golgi is an independent organelle has been a long-standing question in the field. It was agreed at the meeting that considerable evidence now supports the view that the Golgi is an autonomous organelle that can be maintained independently of the endoplasmic reticulum. Cisternal maturation - whereby Golgi cisternae form de novo at the cis face, mature and then dissipate at the trans face - emerged as the favoured model for how cargo are transported across the Golgi, bolstered by evidence from both yeast cells and mammalian data. However, mechanism(s) of Golgi maturation are still unclear; COPI-coated vesicles, which now have an established role in retrograde transport between the Golgi and the endoplasmic reticulum, may act in cisternal maturation, but unambiguous evidence supporting such a view is lacking. Whereas several studies have now noted the existence of tubular connections between Golgi cisternae, their frequency, duration and functional significance for cargo transport remain controversial. Addressing the importance of tubular connections and mechanisms of their formation are important future challenges. It will also be necessary to determine whether specialized domains exist within the Golgi and to define their role in cargo transport. Commenting on the success of the meeting, Ben Glick (University of Chicago) noted, "I think all of us emerged from the meeting with a clearer understanding of how and why our interpretations differed. The meeting summary was repeatedly revised in response to input from the participants until everyone was comfortable with the language. This type of frank, civil conversation is a benefit to science."

This journal has published papers in various areas of controversy, and these papers are subject to the same criteria applied to all papers we publish, namely, that the evidence presented is solid and reproducible. In all cases, the journal is committed to providing a rigorous and fair peer review of papers, ideally by involving referees with diverse perspectives. Of course, this is not possible without the cooperation of reviewers who must judge the merits of a work on the strength of the data presented in the study. The burden of proof required can often be higher when trying to disprove previous models and this may particularly be the case for papers presenting provocative ideas or addressing debated issues.

\section{Advising the government}

\section{The dismissal of a senior science advisor in the UK has lead to a debate on the role of expert advice in crafting public policy.}

Professor David Nutt, chair of the Advisory Council on the Misuse of Drugs, an independent advisory body, was forced to step down in October 2009 following statements that were viewed as potentially damaging to the government's efforts to provide a clear directive on drug abuse. The dismissal led to uproar in the scientific community as several prominent scientists from the Royal Society, the Wellcome Trust and the Medical Research Council rallied to Nutt's support. Tension between the scientific community's position and public policy on issues with societal implications is not unexpected. Cell biologists will remember that in 2004, Elizabeth Blackburn was no longer welcome on the Council for Bioethics under the Bush administration for her views on stem cell research.

Clearly, governments must balance recommendations from experts against various other social, ethical and economic issues when framing public policy. But summarily dismissing scientific advice or retaliating against experts who voice opposition to specific policies will only stifle debate and discourage independent input. Expecting independent advisors to endorse governmental policies that reject evidence-based claims would not only erode their credibility, but would undermine the role of expert advice.

Government agenda will not always coincide with the advice offered by experts. Providing greater transparency into why certain recommendations were rejected would be helpful and, in light of recent events, the UK government has been urged by the scientific community to adopt measures that would encourage more openness when expert advice is rejected. As governments are increasingly faced with the challenges of developing sustainable policies in areas as diverse as stem cell research, pandemic response, energy and climate change, sound and independent scientific advice is crucial; public trust depends on it. 